\title{
Requerimentos de polinização da goiabeira
}

\author{
Pollination requeriments of guava
}

\author{
José Everton Alves ${ }^{\mathrm{I}}$ Breno Magalhães Freitas ${ }^{\mathrm{II}}$
}

\section{RESUMO}

A goiabeira (Psidium guajava) é uma planta muito cultivada no Nordeste brasileiro, onde seus frutos têm elevada importância econômica, porém poucas pesquisas referem-se aos seus requerimentos de polinização. Estes requerimentos, quando conhecidos, podem ajudar no direcionamento do manejo de pomares e de agentes polinizadores visando a melhorar a produtividade das culturas. Assim sendo, o presente trabalho tem por objetivo investigar os requerimentos de polinização da goiabeira. O estudo foi desenvolvido com a cultivar "paluma" e constou de tratamentos de polinização livre, polinização restrita, autopolinização manual, polinização cruzada manual com pólen da mesma e de outra cultivar. Os resultados mostraram que a goiabeira produz frutos principalmente quando visitadas por agentes bióticos, pois, dentre as flores que foram protegidas das visitas desses agentes polinizadores, somente $15,09 \%$ delas produziram frutos. Apesar de vingarem frutos quando autopolinizada, a goiabeira beneficia-se mais da polinização cruzada, pois incrementa sua produção em até 39,5\%. Conclui-se que a presença nos pomares de agentes bióticos promovendo polinização cruzada é necessária para maximizar a produtividade da cultura.

Palavras-chave: Psidium guajava, autopolinização, polinização cruzada.

\section{ABSTRACT}

Guava (Psidium guajava) is largely cultivated in Northeastern Brazil where it is a very important crop. However few researches have investigated the plant pollination requirements. This knowledge can help in managing orchards to improve crop productivity. Therefore, the present study is aimed at investigating the pollination requirements of guava. The study was carried out with cultivar paluma and treatments of open pollination, restricted pollination, hand self-pollination and hand cross pollination among plants of the same and different cultivars were tested. Guava set fruits when pollinated by wind or biotic agents, but flowers protected from flower visitors set only $15.09 \%$. Guava flowers set fruits when were hand self-pollinated, but cross pollinated flowers showed better results because raised fruit production up to $39.5 \%$. The presence of biotic pollinators promoting cross pollination in guava orchards seems to be necessary to maximize crop productivity.

Key words: Psidium guajava, self pollination, cross pollination.

\section{INTRODUÇÃO}

A goiabeira (Psidium guajava) é uma planta de grande importância econômica para o Brasil, que foi em 2004 o terceiro maior produtor mundial, depois de China e Índia (FRANCISCO et al. 2006). Esta cultura contribuiu em 2004 com 174,4 milhões de reais pela produção de 408,28 mil toneladas e uma produtividade aproximada de $21,7 \mathrm{t} \mathrm{ha}^{-1}$, sendo cultivada principalmente nos Estados de São Paulo, Pernambuco e Bahia, que juntos produziram em 2004 aproximadamente $79 \%$ da produção nacional (IBGE, 2006). Entretanto, pouco se sabe sobre as necessidades de polinização da goiabeira e de possíveis perdas de produtividade devido à falta de polinização adequada das flores.

Considerando a receptividade do estigma, trabalhos encontrados na literatura são muito divergentes. Enquanto SINGH \& SEHGAL (1968)

IUniversidade Estadual Vale do Acaraú (UVA), Av. da Universidade, 850, Campus da Betânia, 62040-370, Sobral, CE, Brasil. E-mail: professoreverton@msn.com. Autor para correspondência.

"Departamento de Zootecnia, Centro de Ciências Agrárias (CCA), Universidade Federal do Ceará (UFC), CP 12168, Campus do Pici, 60021-970, Fortaleza, CE, Brasil. E-mail: freitas@ufc.br. 
afirmam que o estigma já se torna receptivo dois dias antes da antese, BOTI (2001) sugere que ele fica receptivo na pré-antese e assim permanece por 30 horas. Por outro lado, SOUBIHE SOBRINHO (1951) alega que a receptividade do estigma inicia-se no momento da antese, enquanto DASARATHY (1951) e BALASUBRAHMANYAN (1959) afirmam que esta só acontece 2 a 3 horas após a abertura da flor.

Analisando-se a parte masculina da flor, verificou-se que o pólen mais freqüentemente depositado nos estigmas de $\boldsymbol{P}$. guajava é o da própria flor, havendo possibilidades de ocorrer a autopolinização (SINGH \& SEGHAL, 1968; SOUBIHE SOBRINHO, 1951). Este tipo de polinização seria possível, pois BOTI (2001) afirma que o pólen da goiabeira não apresenta auto-incompatibilidade. Porém, SETH (1960) e HIRANO \& NAKASONE (1969) encontraram auto-incompatibilidade parcial na goiabeira. Nenhuma outra forma de restrição à autopolinização em $\boldsymbol{P}$. guajava foi encontrada na literatura.

A polinização cruzada foi considerada por alguns autores como sendo a forma mais freqüente de polinização em $\boldsymbol{P}$. guajava (DASARATHY, 1951; BALASUBRAHMANYAN, 1959). Esta afirmação é reforçada por duas características. A primeira é que a morfologia da flor da goiabeira, aponta para uma tendência à melitofilia por serem as flores de cor branca, terem antese durante o dia, apresentarem odores adocicados, flores sem profundidade e anteras com bastante pólen (FÆGRI \& VAN DER PIJL, 1979). Já a segunda característica é que, de fato, as flores da goiabeira são muito visitadas por abelhas solitárias e sociais, como encontrado por SOUBIHE SOBRINHO (1951), SOUBIHE SOBRINHO \& GURGEL (1962), HEDSTROM(1988), MEDINA, (1988), HEARD(1999), ALVES (2000) e BOTI (2001).

O aumento na produtividade de frutos, a produção de frutos de maior massa e o número de sementes são alguns dos benefícios que uma polinização bem sucedida pode promover às culturas de importância econômica (FREE, 1993). Por isso, esses parâmetros são muito usados em estudos de requerimentos de polinização (FREITAS, 1995; FREITAS \& PAXTON, 1996; PEREIRA \& FREITAS, 2002). Entretanto, na goiabeira, somente ALVES (2000) comparou diferentes tipos de polinização e constatou que a polinização cruzada produz significativamente mais frutos do que a autopolinização e a polinização restrita.

Considerando-se as poucas informações disponíveis na literatura e suas contradições, realizouse o presente trabalho com o objetivo de estudar os requerimentos de polinização da goiabeira visando a determinar o tipo de polinização mais adequado para alcançar o máximo do potencial produtivo nesta cultura.

\section{MATERIAL E MÉTODOS}

O trabalho foi conduzido em um pomar de 9 ha de goiabeira cv. "paluma”, em São Gonçalo do Amarante, Ceará, (3³6’22'’ S e 3858'07'’ W e altitude de 15,92m). O clima da região é quente semi-árido, com pluviosidade média de 1100mm anuais e duas estações bem definidas: chuvosa de janeiro a junho, em que 90\% das precipitações ocorrem, e seca, de julho a dezembro (IPLANCE, 1993).

A condução dos experimentos ocorreu durante os meses de setembro a fevereiro, quando foram registradas temperatura média de $33,6+1,9^{\circ} \mathrm{C}$, umidade relativa do ar de $65,8+8,6 \%$ e velocidade média dos ventos de $3,5+0,7 \mathrm{~m} \mathrm{~s}^{-1}$.

Os tratamentos foram distribuídos em 120 plantas escolhidas aleatoriamente do pomar de mais de 3.000 plantas. As plantas floresceram na estação seca devido à indução floral por meio de poda sistemática nos galhos, associada à irrigação por microaspersão. Aleatoriamente, foram escolhidos 533 botões florais, no máximo dez em cada planta, que foram etiquetados e ensacados. Para todos os tratamentos, utilizou-se, como proteção dos botões florais, flores e frutos, sacos de filó de nylon, com tamanho de $20 \mathrm{x}$ $20 \mathrm{~cm}$ e malha de $1 \times 1 \mathrm{~mm}$.

Foram aplicados os diferentes tratamentos como está discriminado a seguir. Polinização livre (T1): visando a identificar o nível de polinização natural das flores pela ação dos agentes polinizadores existentes no pomar, 60 flores da cv. "paluma" foram etiquetadas e acompanhadas durante toda a evolução. Três dias após a antese, foram protegidas da ação de pragas, permanecendo assim até a queda por não-vingamento ou colheita do fruto. Polinização restrita com flores emasculadas (T2): para investigar o papel do vento na polinização da goiabeira, foram ensacados 106 botões florais e, após a antese, providenciou-se a emasculação. Após isso, os botões foram etiquetados e permaneceram ensacados também até a retirada dos frutos. A emasculação foi efetuada para não haver contaminação com o próprio pólen da flor durante o movimento dos galhos. Autopolinização (T3): um número de 100 botões florais, que abririam no dia seguinte, foram ensacados e ficaram protegidos da visita de qualquer possível polinizador. Quando essas flores abriram, a partir de 04h30min, foi retirado o saco de proteção de cada flor e, em seguida, realizou-se o toque das anteras de três flores diferentes, da mesma 
planta, no estigma da flor a ser polinizada. A seguir, as flores polinizadas foram ensacadas novamente, deixando-as bem isoladas e em seguida foram etiquetadas. Os sacos permaneceram nas plantas até a queda ou colheita dos frutos. Polinização manual cruzada dentro da mesma cultivar (T4): este tratamento foi realizado em 169 flores e seguiu a mesma metodologia da autopolinização, diferindo apenas na origem da flor doadora de pólen, o qual, neste caso era de outra planta da mesma cultivar "paluma”, sendo que além disso, após a polinização, as flores eram emasculadas com o auxílio de uma tesoura fina para evitar uma possível contaminação com o pólen da mesma planta. Polinização manual cruzada entre cultivares diferentes (T5): a metodologia utilizada neste tratamento foi semelhante à anterior, em que foi executada manualmente a polinização de 98 flores. As flores doadoras de pólen eram de uma cultivar de goiaba branca presente em uma área próxima, mas não vizinhas.

Os frutos que alcançaram o ponto de colheita tiveram sua massa aferida e suas sementes contadas para obtenção da média do número de sementes por fruto. Este dado avalia o sucesso que os grãos de pólen tiveram na fecundação dos óvulos após todo o processo de polinização da flor.

Foi observado o vingamento dos frutos aos sete e trinta dias após a polinização. Os dados de queda por não-vingamento tinham um caráter binomial (fruto caído $=0 \mathrm{X}$ fruto não-caído $=1$ ) e por isso foram analisados pelo teste não paramétrico de Qui-quadrado. Já os dados de massa total do fruto e número médio de sementes por fruto foram submetidos à análise de variância.

\section{RESULTADOS E DISCUSSÃO}

Aos sete dias após a abertura das flores, $100 \%$ dos frutos vingaram em todos os tratamentos
(Tabela 1). Entre o sétimo e o trigésimo dia após a polinização, observaram-se diferenças significativas $\left(\chi^{2}=106,499, \mathrm{gl}=4, \mathrm{P}<0,05\right)$ entre os tratamentos testados no tocante à retenção dos frutos vingados. $\mathrm{A}$ polinização cruzada entre plantas da mesma cultivar e entre plantas de diferentes cultivares, assim como a polinização livre, foram os tratamentos que apresentaram os melhores resultados na retenção dos frutos $(\mathrm{P}<0,05)$ (Tabela 1$)$.

A colheita dos frutos $(n=533)$ ocorreu, em média, aos 120 dias após a polinização das flores. O número de frutos colhidos ao final do experimento foi igual ao número de frutos aos 30 dias após a polinização das flores em todos os tratamentos (Tabela 1).

Na colheita, os melhores resultados em número de frutos vingados foram obtidos nos tratamentos de polinização cruzada $(\mathrm{P}>0,05)$, usando o pólen da mesma cultivar ou de uma cultivar diferente, e no tratamento de polinização livre (61,6\%). Os demais tratamentos não atingiram percentuais de frutificação satisfatórios, ficando abaixo de $30 \%$ de frutos vingados (Tabela 1).

A goiabeira cv. "paluma” produziu frutos sob qualquer uma das circunstâncias de polinização testadas neste experimento. Mesmo quando as flores foram emasculadas e impedidas de visitas de insetos, $15,1 \%$ das flores geraram frutos (Tabela 1 ). Isso indica que talvez o vento possa desempenhar algum papel na polinização ou que houve contaminação de pólen da própria flor antes da antese no tratamento autopolinização. Nesse sentido, DASARATHY (1951) e BALASUBRAHMANYAN (1959) afirmaram que os estigmas da goiabeira somente se tornam receptivos 2 a 3 horas após a abertura da flor. Para SOUBIHE SOBRINHO (1951), a deiscência das anteras e a receptividade do estigma ocorrem durante a antese da flor. Já BOTI (2001) afirmou que a viabilidade do pólen e a receptividade do estigma ocorrem desde a pré-

Tabela 1 - Vingamento e colheita dos frutos na goiabeira (cv. "paluma”) aos 7 e aproximadamente 120 dias respectivamente sob cinco formas de polinização das flores.

\begin{tabular}{|c|c|c|c|c|c|}
\hline \multirow[t]{2}{*}{ Tratamentos } & \multirow[t]{2}{*}{$\mathrm{N}^{\mathrm{o}}$ de flores } & \multicolumn{2}{|c|}{ Frutos vingados } & \multicolumn{2}{|c|}{ Frutos colhidos } \\
\hline & & Número aos 7 dias & $(\%)$ & Número & $(\%)$ \\
\hline Polinização livre sem desbaste inicial & 60 & $60 \mathrm{a}$ & $(100,00)$ & $37 \mathrm{a}$ & $(61,67)$ \\
\hline Polinização restrita com flores emasculadas & 106 & $106 \mathrm{a}$ & $(100,00)$ & $16 \mathrm{c}$ & $(15,09)$ \\
\hline Autopolinização & 100 & $100 \mathrm{a}$ & $(100,00)$ & $28 \mathrm{~b}$ & $(28,00)$ \\
\hline $\begin{array}{l}\text { Polinização manual cruzada entre plantas da } \\
\text { mesma cultivar }\end{array}$ & 169 & 169 a & $(100,00)$ & $114 \mathrm{a}$ & $(67,46)$ \\
\hline $\begin{array}{l}\text { Polinização manual cruzada entre plantas de } \\
\text { cultivares diferentes }\end{array}$ & 98 & $98 \mathrm{a}$ & $(100,00)$ & 66 a & $(67,35)$ \\
\hline Total & 533 & 533 & - & 261 & - \\
\hline
\end{tabular}

Valores seguidos pelas mesmas letras na coluna não diferem significativamente (Teste de Tukey) $\mathrm{P}<0,05$. 
antese, mas com seus respectivos picos durante a abertura da flor.

Neste experimento, foi encontrada, em 91,5\% das flores ( $\mathrm{n}=59)$, uma pétala modificada em forma de colher, que cobre completamente o estigma, protegendo-o enquanto a flor ainda está fechada, e o expondo somente após a antese das flores, no momento em que o estigma já está posicionado acima das anteras (Figura 1). Esta hercogamia não havia sido ainda relatada na literatura em $\boldsymbol{P}$. guajava, porém a proteção do estigma antes da deiscência das anteras, ou que o mesmo se torne receptivo antes ou após a liberação do pólen da própria flor, são estratégias utilizadas por várias outras espécies vegetais para prevenir a autopolinização (FREE, 1993). No entanto, não se pode concluir se esta pétala evoluiu na espécie com o propósito de dificultar a autopolinização ou se ela resulta das diversas manipulações genéticas dos processos de seleção realizados por geneticistas e que originaram a cultivar estudada ("paluma”).

A produção de frutos por autopolinização manual foi significativamente inferior $(\mathrm{P}<0,05)$ àquela produzida por polinização livre ou polinização cruzada (intra e intercultivares). Este resultado provavelmente foi devido a uma auto-incompatibilidade, conforme citado por SETH (1960) e HIRANO \& NAKASONE
(1969). A polinização cruzada entre a cultivar de goiaba branca e a cultivar "paluma” apresentou os melhores resultados na produção de frutos, não sendo verificada qualquer incompatibilidade entre as cultivares estudadas. Estes resultados corroboram as afirmativas de que o principal tipo de polinização ocorrido na goiabeira seja a polinização cruzada (DASARATHY, 1951; BALASUBRAHMANYAN, 1959).

Os bons resultados obtidos com a polinização livre nesta pesquisa são explicados pela intensa movimentação dos insetos entre flores de diferentes plantas de P. guajava, favorecendo a polinização cruzada e compensando qualquer autoincompatibilidade do pólen da própria flor que tenha sido depositado no estigma. Esta hipótese é reforçada pela síndrome de polinização melitófila da goiabeira e pelo relato de várias espécies de abelhas visitando as flores, como Apis mellífera (SOUBIHE SOBRINHO, 1951; SOUBIHE SOBRINHO \& GURGEL, 1962; ALVES, 2000; HEDSTROM, 1988), A. dorsata e A. indica (MEDINA, 1988), abelhas sem ferrão (HEARD, 1999), espécies do gênero Trigona, Bombus mexicanus e Xylocopa sp. (HEDSTROM, 1988), Centris aenea e Melipona scutellaris (CASTRO, 2002), Melipona subnitida e Partamona cupira (ALVES \& FREITAS, 2006), Epicharis flava, Eulaema nigrita,

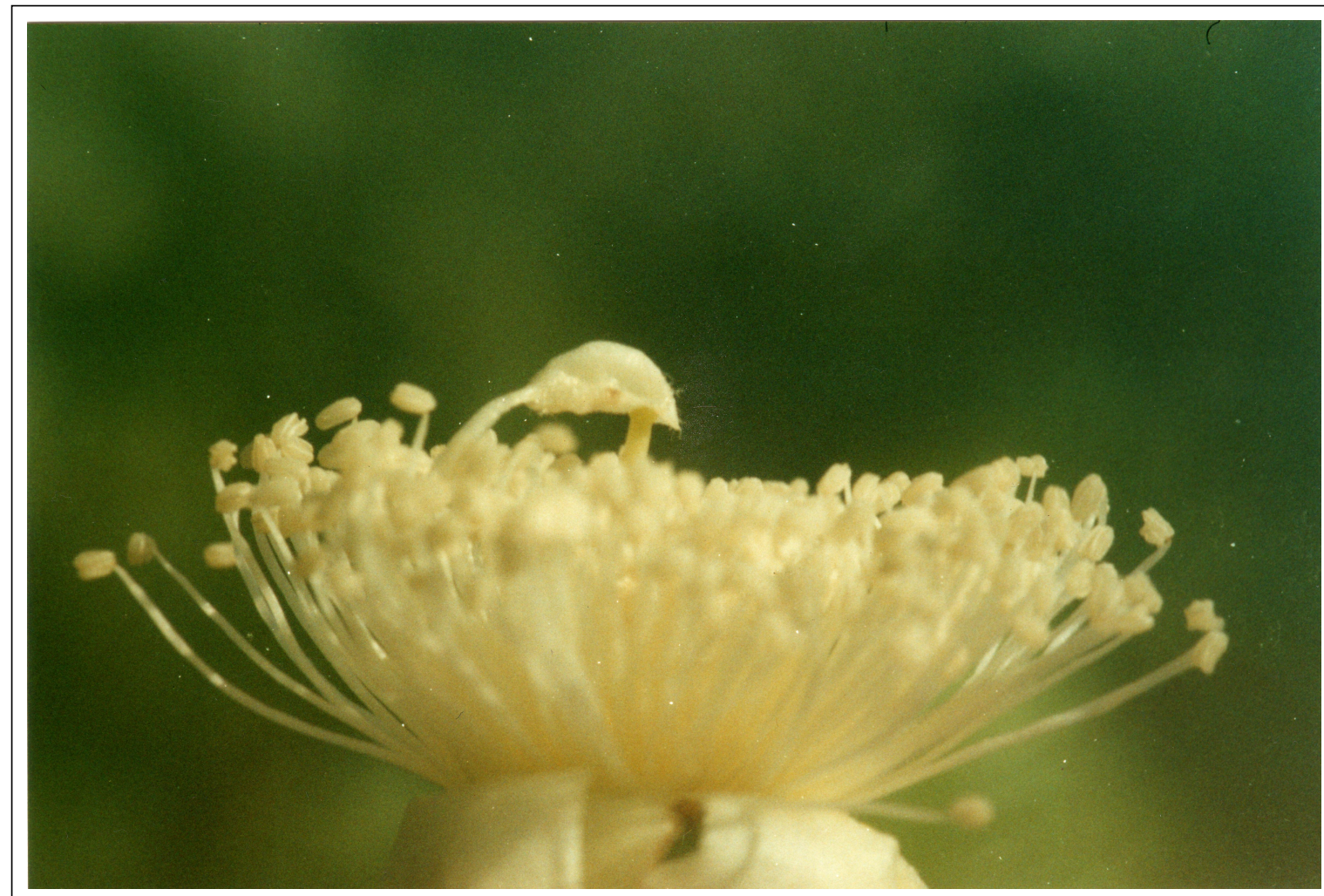

Figura 1 - Flor de goiabeira (Psidium guajava L.) no momento da antese apresentando uma de suas pétalas modificadas prevenindo a autopolinização. 
Augochlroropsis patens, Centris tarsata, Euglossa sp., Oxaea flavecens, Oxytrigona sp., Exomalopsis auropilosa, Xylocopa frontalis e Bombus morio (BOTI, 2001). Neste trabalho, foram encontradas como importantes visitantes florais as abelhas Apis mellifera, Xylocopa frontalis, Trigona spinipes, Melipona subnitida e Partamona cupira.

O percentual de frutos colhidos como produto da polinização livre (61,6\%) assemelha-se com os resultados de 62 a $82 \%$ encontrados por RAY \& CHRONKAR (1981) e de 54 a 90\% de SINGH \& SEHGAL (1968), na Índia. Este declínio no percentual dos frutos vingados foi devido à queda dos frutos jovens, que ocorreu sete dias após a polinização. Trabalhos mostraram que essa perda poderia ter sido devida à ação de pássaros, fatores climáticos e/ou distúrbios fisiológicos (MEDINA, 1988). Porém, durante este experimento, a ação de pássaros não foi a responsável pela queda dos frutos, que ocorreu quando os frutos apresentaram diâmetro de aproximadamente $3 \mathrm{~cm}$.

A massa média dos frutos colhidos foi de 149,5 ( 70,4 g ( $\mathrm{n}=259)$, estando dentro do intervalo de 140 a 250 gramas sugerido por PEREIRA et al. (1983) para a cultivar "paluma”. Houve diferenças significativas (F4, $313=5,433 ; \mathrm{gl}=4 ; \mathrm{P}<0,05$ ) para a massa dos frutos nos diferentes tratamentos (Tabela 2). Os frutos oriundos de polinização cruzada tiveram uma massa significativamente maior do que os frutos produzidos no tratamento de polinização restrita. Este, por sua vez, não diferiu da autopolinização e da polinização livre. Estes resultados indicam que a polinização cruzada e a polinização livre produzem frutos de massa maior que a polinização restrita, talvez por depositarem um maior número de grãos de pólen viáveis no estigma, o que levaria à fecundação de mais óvulos e ao maior desenvolvimento do fruto (Tabela 2).
Foram observadas diferenças significativas (F4, $313=9,108 ; \mathrm{gl}=4 ; \mathrm{P}<0,05)$ nos diferentes tratamentos com relação ao número médio de sementes por fruto. Os resultados mostraram que as flores que foram polinizadas com pólen de outra cultivar ou que receberam visitas irrestritas de polinizadores bióticos apresentaram um maior número de sementes por fruto (Tabela 2).

Um maior número de sementes por fruto, na maioria dos casos, não é uma característica desejável na fruticultura (FREE, 1993). Porém, do ponto de vista ecológico, este parâmetro é um indicador do sucesso reprodutivo da planta, pois quanto maior estes números, maiores são as chances da perpetuação dos seus genes ao longo das gerações (ROUBIK, 1989).

No entanto, para ocorrer o vingamento dos frutos da goiabeira, parece haver uma necessidade do desenvolvimento de um número mínimo de sementes que assegurem a produção de hormônios necessários à sua retenção. Dessa forma, poderia haver diferenças nas taxas de retenção dos frutos em função do tipo de polinização, mas os frutos retidos apresentariam uma menor variação quanto ao número de sementes.

\section{CONCLUSÕES}

A goiabeira produz frutos quando polinizada por agentes bióticos ou pelo vento, porém este não é capaz de assegurar bons níveis de produtividade nesta cultura. Apesar de vingar frutos quando autopolinizada, a goiabeira beneficia-se mais da polinização cruzada, podendo incrementar sua produção em até 39,5\% em relação à autopolinização, provavelmente devido a fenômenos de auto-incompatibilidade. Em função destes requerimentos de polinização, é recomendável a presença de agentes polinizadores nos pomares, especialmente abelhas, cujos comportamentos de forrageamento promovem a polinização cruzada.

Tabela 2 - Massa média dos frutos inteiros da goiabeira (cv. “paluma”) e número de sementes vingadas, oriundos de cinco formas de polinização na goiabeira (Psidium guajava).

\begin{tabular}{|c|c|c|c|}
\hline Tratamentos & Número de frutos & Massa média dos frutos (g) & Número médio de sementes/fruto \\
\hline Polinização livre sem desbaste inicial & 37 & $149,22 \pm 10,49 a b$ & $413,56 \pm 17,10$ a \\
\hline Polinização restrita com flores emasculadas & 16 & $148,32 \pm 21,36 b$ & $187,00 \pm 33,66$ с \\
\hline Autopolinização manual & 28 & $132,21 \pm 11,25 \mathrm{ab}$ & $286,21 \pm 27,25$ bc \\
\hline $\begin{array}{l}\text { Polinização manual cruzada entre plantas da } \\
\text { mesma cultivar }\end{array}$ & 114 & $160,13 \pm 6,72 a$ & $328,58 \pm 16,06 b$ \\
\hline $\begin{array}{l}\text { Polinização manual cruzada entre plantas de } \\
\text { cultivares diferentes }\end{array}$ & 66 & $165,29 \pm 8,55$ a & $339,42 \pm 21,35 a b$ \\
\hline Total & 261 & - & - \\
\hline
\end{tabular}

Valores seguidos pelas mesmas letras na coluna não diferem significativamente (Teste de Tukey) a P $<0,05$.

Ciência Rural, v.37, n.5, set-out, 2007. 


\section{AGRADECIMENTOS}

Os autores agradecem à Coordenação de Aperfeiçoamento de Pessoal de Nível Superior (CAPES), pela bolsa de mestrado concedida a José Everton Alves; ao Centro Nacional de Pesquisas (CNPq), pela bolsa de produtividade em pesquisa de Breno Magalhães Freitas, e à FRUTACE, pela permissão do uso de seu pomar e suas instalações.

\section{REFERÊNCIAS}

ALVES, J.E. Eficiência de polinização de cinco espécies de abelhas na polinização da goiabeira (Psidium guajava L.). 2000. 140f. Dissertação (Mestrado em Zootecnia) - Curso de Pós-graduação em Zootecnia, Universidade Federal do Ceará.

ALVES, J.E.; FREITAS, B.M. Comportamento de pastejo e eficiência de polinização de cinco espécies de abelhas em flores de goiabeira. (Psidium guajava L.). Ciência Agronômica. v.37, n.2, p.216-220, 2006.

BALASUBRAHMANYAN, V.R. Studies on blossom biology of guava. Indian Journal of Horticulture, v.16, p.69-75, 1959.

BOTI, J.B. Polinização entomófila da goiabeira (Psidium guajava L., Myrtaceae): Influência da distância de fragmentos florestais em Santa Teresa, Espírito Santo. 2001. 57f. Dissertação (Mestrado em Entomologia) Universidade Federal de Viçosa.

CASTRO, M.S. de. Bee fauna of some tropical and exotic fruits: potential pollinators and their conservation. In: KEVAN P.; IMPERATRIZ FONSECA, V.L. (Eds). Pollinating bees The conservation link between agriculture and nature. Brasília: Ministry of Environment, 2002. p.21-28.

DASARATHY, T.B. The guava. Madras Agriculture Journal, v.38, p.521-527, 1951.

FÆGRI, K., van der PIJL, L. The principles of pollination ecology. 3.ed. Oxford: Pergamon, 1979. 244p.

FRANCISCO, V.L.F. dos S. et al. A cultura da goiabeira em São Paulo. Capturado em 15 jun 2006. Online. Disponível na internet: http://www.iea.sp.gov.br/out/ verTexto.php?codtexto $=1902$.

FREE, J.B. Insect pollination of crops. 2.ed. London: Academic, 1993. 684p.

FREITAS, B.M. The pollination efficiency of foraging bees on apple (Malus domestica Borkh) and cashew (Anacardium occidentale L.). 1995. 197f. Tese (PhD em Apicultura e Polinização) - University of Wales.
FREITAS, B.M.; PAXTON, R.J. The role of wind and insects in cashew (Anacardium occidentale L.) pollination in NE Brazil. Journal of Agricultural Science, v.126, p.319-326, 1996.

HEARD, T.A. The role of stingless bees in crop pollination. Annual Review of Entomology, v.44. p.183-206, 1999.

HEDSTROM, I. Pollen carriers and fruit development of Psidium guajava L. (Myrtaceae) in the Neotropical region. Revista de Biologia Tropical, v.36, n.2B, p.551-553, 1988.

HIRANO, R.T.; NAKASONE, H.Y. Pollen germination and compatibily studies of some Psidium species. Proceedings of the American Society, v.94, p.287-289, 1969.

IBGE. Instituto Brasileiro de Geografia e Estatística. Capturado em 08 jun 2006. Online. Disponível na internet: http://www.sidra.ibge.gov.br/

IPLANCE. Anuário Estatístico do Ceará. Fortaleza: IPLANCE, 1993. 3v. v.3, 1345p.

MEDINA, J.C. Goiaba I - Cultura. In: INSTITUTO DE TECNOLOGIA DE ALIMENTOS (Campinas, SP). Goiaba: cultura, matéria-prima, processamento e aspectos econômicos. 2.ed. rev. ampl. Campinas: ITAL, 1988. p.1-120. (ITAL. Série Frutas Tropicais, 6).

PEREIRA, J.O.P.; FREITAS, B.M. Estudo da biologia floral e requerimentos de polinização do muricizeiro (Byrsonima crassifólia L.). Ciência Agronômica, v.33, p.55-60, 2002.

PEREIRA, F.M. et al. Comportamento e seleção preliminar de nove cultivares de goiabeira (Psidium guajava, L.) na região de Jaboticabal. Journal of the American Society Horticulture Science, v.25, p.253-258, 1983.

RAY, P.K.; CHRONKAR, V.S. Pollination and fruit development studies in guava. South Indian Horticulture, v.29, n.3, p.134137, 1981 .

ROUBIK, D.W. Ecology and natural history of tropical bees. Cambridge/UK: Cambridge University, 1989. 514p.

SETH, J.N. Varietal cross-incompatibility in guava (Psidium guajava L.). Horticulture Adversity, v.4, p.161-164, 1960.

SINGH, R.; SEHGAL, O.P. Studies on the blossom biology of Psidium guajava L. (guava); 2, Pollen studies stigmatal receptivity pollination and fruit set. Indian Journal of Horticulture, v.25, p.52-59, 1968.

SOUBIHE SOBRINHO, J. Estudos básicos para o melhoramento da goiabeira (Psidium guajava L). 1951. 166f. Tese (Doutorado em Fitotecnia) - ESALQ.

SOUBIHE SOBRINHO, J.; GURGEL, J.T.A. Taxa de panmixia na goiabeira (Psidium guajava L.). Bragantia, v.21, n.2, p.15-20, 1962. 